\title{
PERAN EDU-TAINMENT DALAM MEMBANGUN KOMITMEN DAN PERAN NYATA PADA GERAKAN JIHAD KEDAULATAN PANGAN
}

\author{
Cahyono Agus ${ }^{1 / 2)^{*}}$, Bambang Suhartanto ${ }^{1 / 3)}$, Bambang Hendro Sunarminto ${ }^{1 / 4)}$ dan Ali Agus ${ }^{1 / 3)}$ \\ ${ }^{1)}$ Kebun Pendidikan, Penelitian dan Pengembangan Pertanian (KP4) UGM ${ }^{1}$, \\ ${ }^{2)}$ Fakultas Kehutanan UGM , Yogyakarta \\ ${ }^{3)}$ Fakultas Peternakan UGM, Yogjakarta \\ 4) Fakultas Pertanian UGM, Yogjakarta \\ *Corresponding author Email: cahyonoagus@gadjahmada.edu; acahyono@ugm.ac.id
}

\begin{abstract}
ABSTRAK
Paradigma baru pertanian terpadu harus memberdayakan segenap multi-fungsi pertanian terpadu sebagai pemasok utama sandang, pangan, dan papan bagi kehidupan seluruh makluk hidup; juga sebagai gatra lingkungan hidup yang berkelanjutan, penyedia keindahan lingkungan (wisata-agro), penghasil bio-farmaka dan penghasil bio-energi.Gerakan "Jihad Kedaulatan Pangan" (JKP) dalam menumbuh kembangkan kecintaan dalam memproduksi sendiri dan menggunakan produk pangan unggulan lokal secara sungguh-sungguh, tanpa bergantung pada pangan impor lagi. Gerakan ini harus didukung secara sinergi, utuh, terpadu dann yata oleh seluruh pemangku kepentingan agar membentuk jaringan antar ABCG (Academic / akademisi, Business / pedagang swasta, Community / masyarakat, Government / pemerintah) yang erat dan nyata. Kedaulatan Pangan dapat digapai dengan mengaplikasikan konsep Pertanian Terpadu melalui strategi 5A (Agro-produksi, Agri-bisnis, Agro-industry, Agro-teknologi, Agrowisata) yang memberdayakan seluruh potensi sumber daya alam, air, hayati, lingkungan, SDM dan manajemen secara menyeluruh, terpadu, utuh dan saling sinergis. Konsep ini harus terpadu dari hulu ke hilir untuk masing-masing komoditas unggulan utama sehingga mempunyai nilai tambah di bidang ekonomi, pelestarian lingkungan, sosial dan budaya secara sinergis. Indonesia mempunyai kemampuan, kemauan dan kesempatan untuk mencapai Kedaulatan Pangan, namun komitmen politik dan ekonomi harus dirorong lagi. Dengan perbaikan peraturan, kepemimpinan, pelaksanaan, SDM, teknologi, sinergisme, dan manajemen di seluruh lini 5A ini, maka diharapkan dapat memperbaiki kelemahan utama komoditas pertanian agar mampu memenuhi standart $3 \mathrm{~K}$ (kuantitas, kualitas dan kontinyuitas) serta bersertifikat halalal thoyiban.Peran pers dan edu-tainment sangat penting untuk meningkatkan image building, kepercayaan, komitmen dan peran nyata seluruh stake holder untuk mendukung program unggulan mendukung Jihad Kedaulatan Pangan.
\end{abstract}

Kata kunci: paradigma baru, perbaikan genetik, pertanian terpadu, rekayasa lingkungan siklus terpadu 


\section{PARADIGMA PERTANIAN TERPADU}

Paradigma industri pertanian yang berkembang setelah Perang Dunia II sampai saat ini ialah bahwa menanam tanaman sebagai masalah individu yang biasanya dianggap tidak berhubungan dengan satu sama lain. Namun demikian paradigm yang baru menuntut keterlibatan para pihak dari berbagai disiplin ilmu untuk berpadu dalam penyelesaian pembangunan pertanian terpadu secara berkelanjutan (Magdof and Weil, 2004; Agus, 2011a,b).

Pertanian terpadu merupakan sistem yang menggabungkan kegiatan pertanian, peternakan, perikanan, kehutanan dan ilmu lain yang terkait dengan pertanian dalam satu lahan, sehingga diharapkan dapat sebagai salah satu solusi alternatif bagi peningkatan produktivitas lahan, program pembangunan \& konservasi lingkungan serta pengembangan desa secara terpadu (agus et al., 2004, 2010a,b, 2011a,b). Diharapkan kebutuhan jangka pendek, menengah dan panjang petani berupa pangan, sandang dan papan akan tercukupi dengan sistem pertanian berbasis agroforestry ini. Hasil pertanian dan perikanan diharapkan mampu mencukupi kehidupan jangka pendek, sedangkan hasil peternakan dan perkebunan dapat dimanfaatkan untuk kehidupan jangka menengah. Penjualan hasil kebun dan hasil hutan rakyat sekarang dipercaya mampu mencukupi kebutuhan membayar biaya sekolah, rumah sakit, hajatan sunatan, mantenan dan kebutuhan jangka panjang lain. Dengan demikian, sistem agroforestry mampu memberikan pendapatan harian, bulanan, tahunan maupun dekade-an bagi petani.

Model Integrated farming dikembangkan juga oleh KP4 UGM dengan beberapa kajian lebih mendalam melalui: ICM (Integrated Crop Management atauPengelolaan tanaman terpadu), INM (Integrated Nutrient Management atau pengelolaan hara terpadu), IPM (Integrated Pest Management atau pengelolaan hama terpadu) danIMM (Integrated Soil Moisture Management atau pengelolaan air terpadu) (Agus 2006b)

\section{INTEGRATED BIO-CYCLE FARMING SYSTEM}

Usaha pertanian di seluruh dunia relatif dapat berproduksi dengan baik dan berkelanjutan hanya apabila ada asupan energi yang besar, dan kadang harus berkompromi secara ekonomi dibanding untuk keberlanjutan ekosistem (Chan, 2006). Model Integrated Biocycle Farming System (IBFS) adalah sistem pertanian alternatif yang memadukan secara harmonis antara sektor pertanian (pertanian, hortikultura, perkebunan, peternakan, perikanan, kehutanan dsb) dengan non-pertanian (pemukiman, agro-industri, wisata, industri dsb) yang 
dikelola berdasarkan landscape ecological management dalam satu kesatuan wilayah terpadu (agropolitan). Inovasi drastis dan berarti dalam IBFS adalah introduksi digester \& basin serta organisme pro-biotik dalam proses perlakuan limbah organik.Usaha pertanian besar, usaha pengepakan daging dan ikan, dan berbagai agro-industri sekarang telah mampu mencukupi kebutuhan energinya sendiri, disamping mempunyai pengaruh yang besar terhadap pengkayaan nutrient dalam volume besar pada kolam ikan, dan 'fertigation' (fertilization \& irrigation, pemupukan dan pengairan) pada berbagai macam tanaman semusim dan lainnya.

Kebun Pendidikan, Penelitian, dan Pengembangan Pertanian Universitas Gadjah Mada (KP4 UGM) sebagai salah satu Unit Penunjang Universitas yang memberikan layanan kepada civitas akademika UGM maupun kepada masyarakat di luar UGM, mengembangkan Program Artificial and functional conservation yang merupakan suatu kegiatan terpadu dalam sistem pertanian terpadu berbasis Education for Sustainable Development (EfSD), yang mensinergiskan aspek ekonomi, lingkungan dan social budaya secara terpadu, dengan melibatkanpelestarian pemanfaatan keanekaragaman tanaman obat Indonesia yang merupakan suatu kegiatan terpadu, melibatkan institusi, berbagai disiplin ilmu.

KP4 UGM mengembangan Pusat Unggulan (Center of Excellence) berupa Pertanian Terpadu, yang mengacu pada konsep pembangunan berkelanjutan (sustainable development), dengan mengelola sumber daya alam, sumber daya hayati dan sumber daya lingkungan secara optimal. Program ini mempunyai ciri pokok dan merupakan pengejewantahan program Pendidikan untuk Pembangunan Berkelanjutan (Education for Sustainable Development) yang harus memperhatikan gatra peningkatan nilai ekonomi, kelestarian lingkungan, keadilan sosial dan budaya, secara sinergis dan optimal. Keseimbangan produksi dan konsumsi merupakan salah point yang harus dikembangkan, sehingga dalam satu kesatuan lahan tersebut mampu memproduksi pangan, pakan, papan, pupuk, obat herbal, dan wisata.

Program percepatan pertumbuhan optimal (Accelerated optimal growth) didukung peningkatan genetik dan perbaikan lingkungan tempat tumbuh (Agus et al., 2012a). Untuk mendukung peningkatan genetik, maka telah dikembangkan Gama Anggrek, Gama Melon, Gama Ayam, Gama Jagung, Gama Padi dan Gama Sapi Bali. Program perbaikan lingkungan tempat tumbuh untuk memperbaiki resim lengas, resim temperatur dan resim unsur hara telah dilakukan melalui Gama Biogas, Gama Pot organik, Gama pertanian terpadu. 


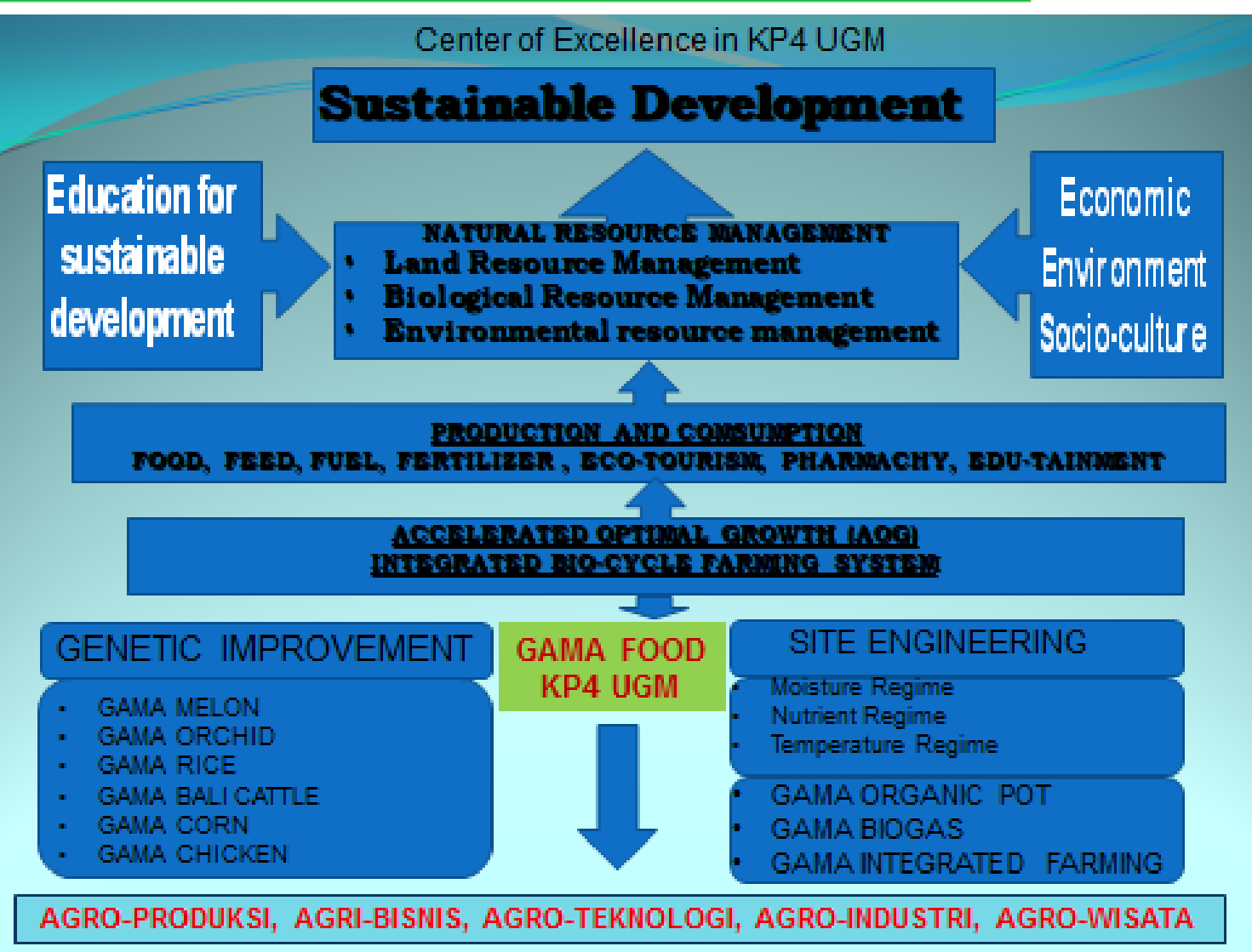

Gambar 1. Pengembangan Pusat Unggulan Pertanian Terpadu di KP4 UGM

Pemanfaatan lahan secara harmonis, menyeluruh (holistic) dan terpadu (integrated) serta berkelanjutan (sustainable) untuk berbagai peruntukan, yaitu: (i) produksi biomassa (sektor pertanian), (ii) lingkungan hidup (iii) habitat biologi dan konservasi gen. (iv) ruang infra-stuktur, (v) sumber daya alam, dan (vi) estetika dan budaya, merupakan ciri utama dalam sistem IBFS. Masing-masing anasir bentang lahan tidak boleh saling menonjolkan kepentingan sektoral sendiri saja namun harus saling berkaitan dan mendukung secara harmonis. Output dan outcomes sistem lebih diutamakan dibandingkan keluaran masing-masing anasir pembentuknya.

Karakteristik kunci dari IBFS yang dikembangkan di KP4 UGM adalah meliputi 9 anasir utama (Agus, 2006, 2010), yang mempunyai nilai lebih unggul dibanding ssstem pertanian LOW INPUT/INTEGRATED- pertanian input rendah/ terpadu(Stockdale \& Cookson, 2003, Chan, 2006), ORGANIC FARMING - pertanian organik(IFOAM, 1998),BIO-DYNAMIC - pertanian biodinamik(Koept et al., 1976), AGROFORESTRY - agroforestri(Stockdale \& Cookson, 2003).IBFS merupakan integrasi dari sektor pertanian dan non-pertanian, melalui pendaur ulangan bahan organik yang berasal dari sector pertanian maupun non-pertanian secara terpadu.Suplai 
makanan yang diproduksi dari desa untuk dikirim ke kota telah mengakibatkan defisit bahan organik di desa, sehingga tumpukan bahan organik di kota perlu diaur ulangkan ke system pertanian yang banyak terdapat di desa(Agus, 2006a, b, 2010a, b, 2012a). IBFS mengedepankan nilai lingkungan, nilai estetika, nilai social, nilai budaya dannilai ekonomi secara harmonis dan seimbang, tanpa ada yang mendominiasi. Dengan demikian bukan melulu mementingkan nilai ekonomi semata sehingga terpaksa menghilangkan faktor lainnya, seperti yang dilakukan oleh praktis bisnis pertanian yang dilakukan oleh pengusaha besar, namun harus mampu mengharmoniskan seluruh aspek yang muncul. IBFS juga dilakukan dengan sistem rotasi dan keaneka-ragaman tanaman, sehingga biodiversitas dan siklus tanaman tetap terjaga dan terpelihara untuk mendukung pertumbuhan dan perkembangan bagi kehidupan dan lingkungan.Inovasi besar di bidang bio-teknologi buatan dan fungsional, nanoteknologi, dan pro-biotik merupakan terobosan besar yang harus dilakukan agar terjadi revolusi kehidupan dan lingkungan yang makin berkualitas. Loncatan kualitas kehidupan dan lingkungan pada level yang lebih tinggi dan baik dapat dicapai dengan pemberdayaan bio-nano-teknologi probiotik yang fungsional agar siklus dan kualitas kehidupan makin meningkat(Agus, 2006a, b, 2010a, b, 2012a).

Pengelolaan siklus tertutup organik dan integrasi dalam suatu kawasan terpadu antara ICM, IFM, IPM, IMM, INM merupakan ciri utama dalam IBFS agar terjadi sistem daur tertutup yang mandiri dan berkualitas.Pengelolaan perlindungan bio terpadu dan pengelolaan ekosistem kesehatan, merupakan syarat mutlak agar konsep kembali alam dengan produktivitas serta kualitas hidup dan lingkungan yang lebih baik bisa terjamin dan berkelanjutan.Manajemen ekologi lanskap terpadu dan konsep agropolitan merupakan salah satu strategi penghilangan kotak-kotak egosentris dalam IBFS, sehingga tidak lagi mementingkan ego sector sendiri-sendiri, namun justru harus bersinergis. Dengan demikian pengelelolaan bahan organik harus dikelola dalam satu kesatuan lahan yang luas.Pengelolaan khusus tanaman perlu juga dilakukan karena masing-masing spesies tanaman mempunyai karakter hidup dan produktivitas sendiri-sendiri (Agus \& Wulandari 2012).Selanjutnya, IBFS harus dikelola dalam suatu sistem holistik dan terintegrasi (Agus, 2006a, b, 2010a, b, 2012a).

\section{JIHAD KEDAULATAN PANGAN}

Selama 6 bulan ke depan, sejak Januari sampai Juni 2013 mendatang, masyarakat Indonesia bakal tidak bisa menikmati 6 jenis buah impor. Hal ini konsekuensi dikeluarkannya Permentan nomer 60 Tahun 2012 dan Permendag No 60/2012 soal impor hortikultura, karena tidak mendapatkan Rekomendasi Impor Produk Hortikultura (RIPH). Alasannya karena produk dalam negeri sudah mencukupi kebutuhan pasar domestik. Sebenarnya, ada 13 jenis produk hortikultura yang dilarang masuk ke Indonesia, yaitu 6 jenis buah (durian, nanas, melon, pisang,

Please consider the environment before printing this Journal. 
mangga dan papaya), 4 jenis produk sayuran (kentang, kubis, wortel, cabe), dan 3 produk bunga (krisan, anggrek, heliconia).

Sepanjang tahun 2012, Indonesia mengimpor buah jeruk sebesar 152,2 ribu ton senilai US\$ 148,8 juta, apel sebesar 92,4 ribu ton senilai US\$ 82,2 juta, anggur sebesar 20,4 ribu ton senilai US\$ 44,7 juta, pear sebanyak 69 ribu ton senilai US\$ 55,3 juta, lengkeng sebanyak 29,2 ribu ton senilai US\$ 34 juta, durian sebanyak 1,6 ribu ton senilai US\$ 1,7 juta, kurma mencapai 32,4 ribu ton senilai US\$ 40 juta, dan buah naga 5,2 ribu ton senilai US\$ 4,4 juta. Potensi ini sangat besar dapat direbut untuk memberi kesejahteraan dan kemakmuran sebesar-besarnya bagi seluruh pemangku kepentingan pada komoditas buah-buahan..

Kebijakan ini penting untuk mendukung gerakan "Jihad Kedaulatan Pangan" (JKP) dalam menumbuh kembangkan kecintaan dalam memproduksi sendiri dan menggunakan produk pangan unggulan lokal secara sungguh-sungguh, tanpa bergantung pada pangan impor lagi. Kebijakan ini juga akan memberikan iklim yang kondusif bagi perkembangan lembaga-lembaga riset, petani produsen, konsumen, pedagang, pengelola di bidang hortikultura sekaligus penguatan ekonomi nasional. Namun demikian harus didukung sinergi seluruh pemangku kepentingan agar membentuk jaringan antar ABCG (Academic/akademisi, Business/pedagang swasta, Community/masyarakat, Government/pemerintah) yang erat dan nyata. JKP tidak bisa hanya dibebankan salah satu komponen, namun harus dalam kesatuan utuh yang terpadu. Perlu komitmen dan kontribusi yang besar dan nyata agar jargon tersebut bukan sekedar omong kosong.

Potensi produktivitas sumberdaya alam, air, hayati, lingkungan di Indonesia sepuluh kali lipat dibanding wilayah temperate karena didukung lingkungan tropika yang menyediakan tanah subur, air hujan, sinar matahari, temperatur, keaneka ragaman hayati yang melimpah. Dengan demikian, sungguh ironis kalau Indonesia justru mengimpor buah dan sayuran dari negara-negara temperate yang tingkat produktivitas alamnya jauh lebih rendah.Kita hanya bangga mempunya banyak warisan plasma nutfah dan varitas tanaman unggul, namun justru dicuri negara lain, dan dipasarkan ke Indonesia lagi. 


\section{KENDALA DAN TANTANGAN}

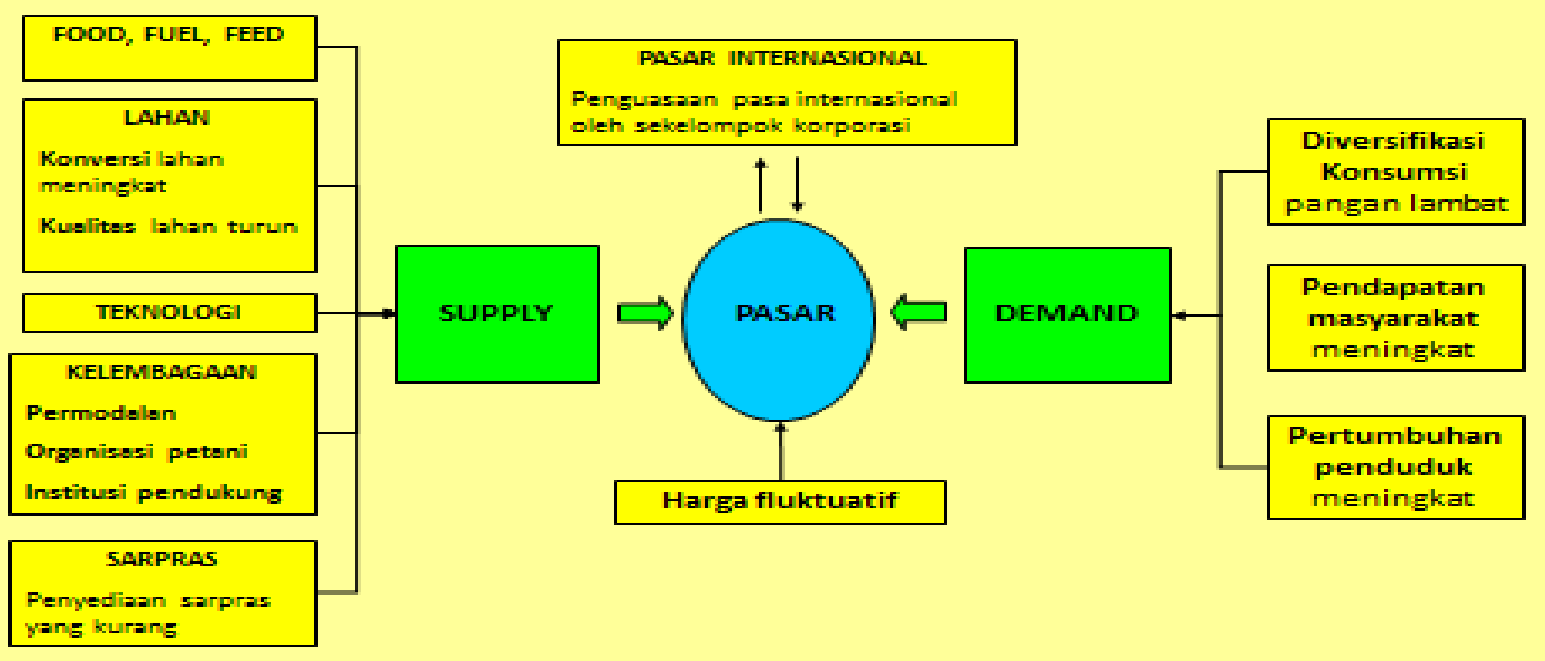

Gambar 2. Kendala dan tantangan Kedaulatan Pangan Indonesia

Sebenarnya, kualitas buah lokal kita jauh lebih segar enak dan terbukti lebih unggul kandungan vitaminnya dibanding buah impor, namun biasanya ukuran kecil, tidak standar, bentuk dan warna yang kurang menarik. Kandungan vitamin C dan A di mangga lokal bisa sepuluh kali lebih tinggi dibanding kandungan mangga impor. Saat ini buah impor dipilih karena cita rasanya yang dianggap memiliki standar, termasuk bentuk dan warna yang lebih menarik, dengan harga yang masih terjangkau dan mengangkat prestise. Namun demikian, hasil riset pernah menemukan buah impor yang mengandung lapisan lilin sebagai pengawet dan residu pestisida berbahaya, yang dapat menyebabkan kanker usus, hati, dan leukeumia,

Kedaulatan Pangan dapat digapai dengan mengaplikasikan konsep Pertanian Terpadu melalui strategi 5A (Agro-produksi, Agri-bisnis, Agro-industry, Agro-teknologi, Agro-wisata) yang memberdayakan seluruh potensi sumber daya alam, air, hayati, lingkungan, SDM dan manajemen secara menyeluruh, terpadu, utuh dan saling sinergis. Konsep ini harus terpadu dari hulu ke hilir untuk masing-masing komoditas unggulan utama sehingga mempunyai nilai tambah di bidang ekonomi, pelestarian lingkungan, sosial dan budaya secara sinergis.. Perbaikan sifat genetik dan lingkungan pertumbuhan jelas akan makin mampu meningkatkan produktivitas lahan, Pola bisnis inti-plasma dalam kesatuan manajemen dan penanganan pasca panen Hi-touch diarahkan agar mampu memberikan nilai tambah dan daya saing komoditas pertanian untuk mencapai kedaulatan pangan nasional dan kesejahteraan masyarakat.

Dengan perbaikan peraturan, kepemimpinan, pelaksanaan, SDM, teknologi, sinergisme, dan manajemen di seluruh lini 5A ini, maka diharapkan dapat memperbaiki kelemahan utama komoditas pertanian agar mampu memenuhi standart 3K (kuantitas, kualitas dan kontinyuitas) 
serta bersertifikat halalal thoyiban. Negara tetangga Malaysia dan Thailand adalah contoh nyata bahwa mereka mampu mengelola sumber dayanya yang lebih terbatas dengan menghasilkan produk buah dan sayuran unggulan yang khas dan terkenal di dunia.Diharapkan Indonesia juga mampu segera mencapai kedaulatan pangan, bahkan ekspor berbagai komoditas pangan utama termasuk buah dan sayuran.

Beberapa perguruan tinggi besar seperti UGM telah mengembangkan Gama Pertanian Terpadu, Gama Melon, Gama Anggrek, Gama Jagung, Gama Kedelai Hitam, Gama Sapi Bali, Gama Ayam, Gama Padi. IPB telah melepas tiga varietas pepaya (Sukma, Carisya, Callina), nanas (Mahkota), dua varietas pisang (Rajabulu Kuning, Unti Sayang), lima varietas manggis (Wanayasa, Puspahiang, Malinau, Marel, Raya) dsb untuk dikontribusikan secara nyata dalam Jihad Kedaulatan Pangan.

\section{PERAN PERS DAN EDU-TAINMENT}

Informasi tentang inovasi dan program unggulan yang mempunyai peran besar dalam pembangunan wilayah dan kesejahteraan masyarakat sangat dinantikan oleh seluruh masyarakat, sehingga menjadi berita yang menarik bagi masyarakat.Masyarakat ilmiah relatif terkungkung dengan sajian gaya ilmiah yang dinilai berat, sulit, ekslusif, egosentris, dan tidak mudah dimenegerti oleh orang awam. Hasil penelitian masih tersimpan rapi pada kalangan terbatas, sehingga penghiliran informasi ilmiah melalui publikasi ilmiah, kebijakan publik oleh pemerintah, teknologi tepat guna kepada masyarakat, serta pengembangan bisnis ke swasta tidak berjalan optimal, bahkan nyaris terhenti.

Pers merupakan penyambung informasi yang dinilai terlalu ilmiah, menjadi informasi popular yang mudah dimengerti masyarakat umum. Kemasan program Edu-tainment akan lebih mendekatkan kepada masyarakat umum, karena lebih mudah menerima informasi ilmiah dengan cara yang lebih menarik dan diterima, bahkan dinantikan sebagaimana programprogram info-tainment di media massa.Pers membutuhkan bahan berita yang dibutuhkan masyarakat, sedangkan penelitian unggulan perguruan tidak bisa diakses dengan mudah oleh masyarakat umum.Sinergisme peran dan saling ketergantungan pers dalam penghiliran informasi penelitian melalui audio visual yang menarik merupakan kunci keberhasilan pendidikan masyarakat secara keseluruhan.

Edutainment adalah seni yang dimainkan oleh seseorang atau sekelompok orang untuk mencapai tujuan yang telah ditentukan (learning process). Media (edutainment) ini mencover dua aktivitas yang berbeda yaitu mendidik dan menghibur pembelajar. Media entertainment seperti televisi, buku, video, dan computer games merupakan media yang selalu digunakan dalam proses pembelajaran. Program Edu-tainment di KP4 UGM untuk menghilirkan programprogram unggulan pertanian terpadu melalui pers telah mendapatkan feed back yang baik,

Please consider the environment before printing this Journal. 
berupa peningkatan apresiasi masyarakat kampus, pemerintah, swasta dan umum untuk memanfaatkan fasilitas untuk proses pembelajaran, serta pembangunan nasional yang berkelanjutan.

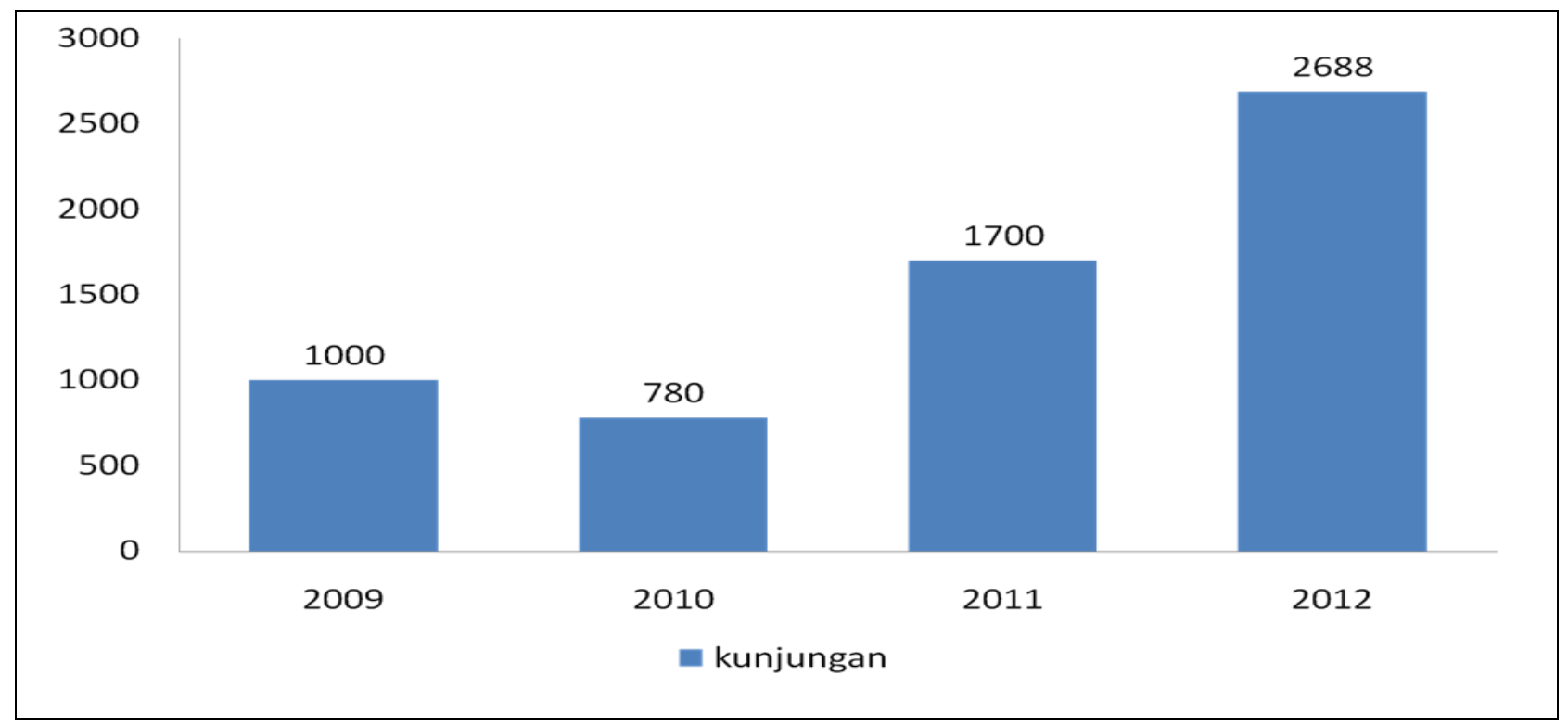

Gambar 3. Jumlah kunjungan pemanfaatan KP4 UGM University Farm dalam program Pertanian Terpadu

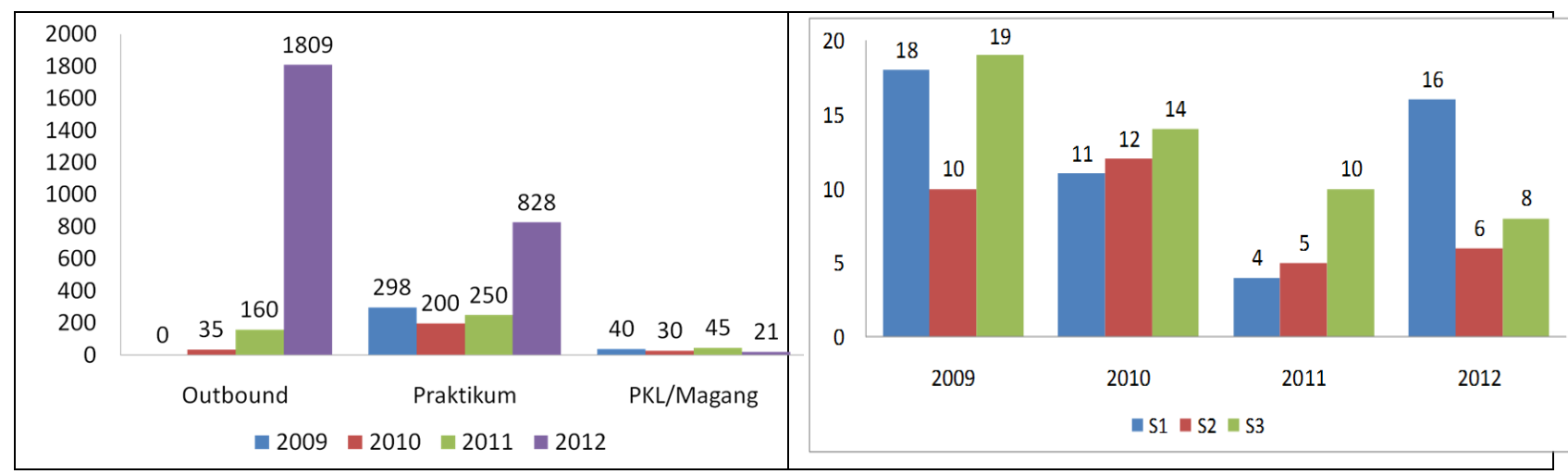

Gambar 4. Jumlah pengunjung yang memanfaatkan KP4 UGM University Farm untuk kegiatan edu-tainment dan tridarma

Image building terhadap unggulan yang tercipta melalui edu-tainment meningkat drastis dengan persepsi seluruh stake holder terhadap lembaga, program dan produknya.Pemanfaatan stake holder untuk melakukan pembelajaran secara formal, in formal dan non formal meningkat dengan drastic (Gambar 3 dan 4). Penyediaan dana dari internal maupun eksternal S) Please consider the environment before printing this Journal. 
meningkat drastis seiring dengan kepercayaan adanya invasi unggulan yang sangat bermanfaata bagi pembangunanberkelanjutan. Peran pers dan edu-tainment sangat penting untuk meningkatkan image building, kepercayaan, komitmen dan peran nyata seluruh stake holder untuk mendukung program unggulan pertanian terpadu mendukung Jihad Kedaulatan Pangan.

\section{KESIMPULAN}

Gerakan "Jihad Kedaulatan Pangan" (JKP) dalam menumbuh kembangkan kecintaan dalam memproduksi sendiri dan menggunakan produk pangan unggulan lokal secara sungguhsungguh, tanpa bergantung pada pangan impor lagi. Gerakan ini harus didukung secara sinergi, utuh, terpadu dann yata oleh seluruh pemangku kepentingan agar membentuk jaringan antar ABCG (Academic / akademisi, Business / pedagang swasta, Community / masyarakat, Government / pemerintah) yang erat dan nyata.

Kedaulatan Pangan dapat digapai dengan mengaplikasikan konsep Pertanian Terpadu melalui strategi 5A (Agro-produksi, Agri-bisnis, Agro-industry, Agro-teknologi, Agro-wisata) yang memberdayakan seluruh potensi sumber daya alam, air, hayati, lingkungan, SDM dan manajemen secara menyeluruh, terpadu, utuh dan saling sinergis. Konsep ini harus terpadu dari hulu ke hilir untuk masing-masing komoditas unggulan utama sehingga mempunyai nilai tambah di bidang ekonomi, pelestarian lingkungan, sosial dan budaya secara sinergis..

Indonesia mempunyai kemampuan, kemauan dan kesempatan untuk mencapai Kedaulatan Pangan, namun komitmen politik dan ekonomi harus dirorong lagi. Dengan perbaikan peraturan, kepemimpinan, pelaksanaan, SDM, teknologi, sinergisme, dan manajemen di seluruh lini 5A ini, maka diharapkan dapat memperbaiki kelemahan utama komoditas pertanian agar mampu memenuhi standart 3K (kuantitas, kualitas dan kontinyuitas) serta bersertifikat halalal thoyiban.

Peran pers dan edu-tainment sangat penting untuk meningkatkan image building, kepercayaan, komitmen dan peran nyata seluruh stake holder untuk mendukung program unggulan mendukung Jihad Kedaulatan Pangan.

\section{REFERENCES}

Agus, C., Karyanto, O., Hardiwinoto, S., Haibara, K., Kita, S. and Toda, H. 2003. Legume cover crop as a soil amendment in short rotation plantation of tropical forest. J. For. Env. 45(1): 13-19.

Agus, C., Karyanto, O., Kita, S., Haibara, K., Toda, H., Hardiwinoto, S., Supriyo, H., Na'iem, M., Wardana, W., Sipayung, M., Khomsatun and Wijoyo, S. 2004. Sustainable site productivity and nutrient management in a short rotation Gmelina arborea plantation in East Kalimantan, Indonesia. New Forest J. 28: 277-285

\footnotetext{
Please consider the environment before printing this Journal.
} 
Agus, C. 2006a. Pengembangan agribisnis berbasis pertanian terpadu di KP4 UGM. Bahan presentasi Pelatihan Agribisnis Berbasis Integrated Farming. KP4 UGM. 8-10 Agustus 2006.

Agus, C. 2006b. Integrated Farming System In ATRDC (Agricultural Training, Research and Development Centre) UGM. Proceeding of International seminar on Agroforestry. INAFE and UGM. Jogjakarta.

Agus, C. 2010a. Organic matter management in UGM University Farm for sustainable food, feed, fiber and fertilizer. Proceeding Seminar onThe $16^{\text {th }}$ Annual International Sustainable Development Research Conference.30 May - 1 June 2010. Hong Kong.

Agus, C. 2010b. Agribisnis berbasis pertanian terpadu. Dalam Sunarminto, B.H. (ed). Pertanian Terpadu untuk mendukung Kedaulatan Pangan Nasional. Penerbit BPFE dan KP4 UGM Yogyakarta. hal 109-127.

Agus, C, Sunarminto, B.H., Suhartanto, B., Pertiwiningrum, A., Setiawan, I. and D Pudjowadi. 2011a. INTEGRATED FARMING FOR SUSTAINABLE LIFE AND ENVIRONMENT. The 17th Annual International Sustainable Development Research Conference "Moving Toward a Sustainable Future: Opportunities and Challenges", hosted by the Earth Institute, Columbia University, New York, New York, USA. May 8 to 10, 2011.

Agus, C. Sunarminto, B.H., Suhartanto, B., Pertiwiningrum, A., Setiawan, I. Wiratni and Pudjowadi, D. 2011b. Integrated Bio-cycles Farming Ssystem for production of Bio-gas through GAMA DIGESTER, GAMA PURIFICATION AND GAMA COMPRESSING. Journal of Japan Institute of Energy 90 (11) : 1086-1090.

Agus, C., Sunarminto, BH., Suhartanto, B., Pertiwiningrum, A., Daryono, BD., Rachmawati, D., and E. Semiarti, E., 2012a. Development of site and genetic improvement in integrated bio-cycles farming system for sustainable development. Presented paper on 18th Annual International Sustainable Development Research Conference. 24-26 June 2012. Univ of Hull, Hull, UK.

Agus, C., Karyanto, O., Hardiwinoto, S., Supriyo, H. and K. Haibara. 2012b. The Potency of Legumes Cover Crops as Soil Amelioration for Integrated Ecosystem Management in Tropical Short Rotation Plantation Forest Area. International Proceedings of Chemical, Biological \& Environmental Engineering vol 41: 145-150. (ISSN: 2010-4018).

Agus, C and D. Wulandari. 2012. The Abundance of Pioneer Vegetation and Their Interaction with Endomycorrhiza at Different Land Qualities after Merapi Eruption. JMHT 18(3): 145154. 
Agus, C. 2012. Pengelolaan Bahan organik: Peran dalam kehiudpan dan ligkungan, BPFE UGM Press. Yogyakarta. 320 hal.

Chan, G,L. 2006. Integrated Farming System. http://www.scizerinm.org/ chanarticle.html. Access 5 September 2006

International Federation of Organic Agriculture Movements, IFOAM. 1998. Basic standards for organic production and processing. IFOAM. Tholey-Theley. Germany.

Stockdale, E.A. and W.R. Cookson. 2003. Sustainable farming systems and their impact on soil biological fertility-some case studies. In Abbott, L.K. and Murphy, D.V. (eds). 2003. Soil biological fertility. A key to sustainable land use in agriculture. Kluwer Ac. Pub. Dordrecht. Pp. 225-239. 